

\section{Nuevas puertas de indagación sobre las prácticas de enseñanza de la geografía escolar}

\section{New Ways of Inquiry on the Teaching Practices of Geography in School \\ Novas formas de indagação sobre as práticas de ensino da geografia da escola}

María Victoria Fernández Caso

Raquel Gurevich*

\section{Resumen}

Este texto parte de la inquietud por proponer nuevas puertas de indagación sobre las prácticas escolares en geografía, a fin de superar los enfoques naturalizantes, acríticos o meramente descriptivos. Se recuperan los resultados de un proyecto de investigación UBACyT en el que convocamos a un grupo de docentes de Geografía a participar de una experiencia de intercambio y reflexión acerca de la elaboración de secuencias didácticas referidas a problemas ambientales. El taller con los docentes se dedicó a revisar enfoques y contenidos acerca de la enseñanza de la geografía, teniendo en cuenta los desarrollos recientes del campo, las transformaciones de la sociedad contemporánea y los nuevos lineamientos curriculares para la Escuela Secundaria en Argentina. También analizamos las secuencias didácticas, considerando qué papel ocupan los conceptos y explicaciones de orden social en los contenidos referidos a problemas ambientales.

\section{Palabras clave}

prácticas escolares; enseñanza de la geografía; lineamientos curriculares 


\section{Abstract}

This text is the result of a concern to propose new ways of investigation on the school practices in geography, in order to overcome the naturalizing, uncritical or merely descriptive approaches. We gather the results of an UBACYT Research Project, in which we call on a group of geography teachers to participate in an experience of exchange and reflection about the development of didactic sequences related to environmental problems. The workshop with teachers was devoted to reviewing approaches and contents on the teaching of geography, taking into account the recent developments in the subject, the transformations of contemporary society and the new curricular guidelines for secondary school in Argentina. We also analyze the didactic sequences, considering the role of concepts and explanations of social order in the contents related to environmental problems.

\section{Resumo}

Este texto surge da preocupação de propor novas formas de investigação sobre as práticas escolares em geografia, para superar as abordagens naturalizadoras, não críticas ou meramente descritivas. Recuperamos os resultados de um projeto de pesquisa UBACyT em que convidamos um grupo de professores de geografia para participar de uma experiência de troca e reflexão sobre o desenvolvimento de sequências didáticas relacionadas a problemas ambientais. A oficina com os professores foi dedicada a revisar abordagens e conteúdos sobre o ensino da geografia, levando em conta os desenvolvimentos recentes no campo, as transformações da sociedade contemporânea e as novas diretrizes curriculares para a Escola Secundária na Argentina. Analisamos também as sequências didáticas, considerando o papel dos conceitos e explicações da ordem social nos conteúdos relacionados a problemas ambientais.

\section{Keywords}

school practices; teaching of geography; curricular guidelines

\section{Palavras-chave}

práticas escolares: ensino da geografia; diretrizes curriculares 
Este texto começa com a preocupação de propor novas formas de investigação sobre as práticas escolares, para superar as abordagens naturalizadoras, não críticas ou meramente descritivas. Recuperamos os resultados de um projeto de pesquisa UBACyT em que chamamos um grupo de professores de Geografia para participar de uma experiência de troca e reflexão sobre o desenvolvimento de seqüências didáticas relacionadas a problemas ambientais. $O$ workshop com professores foi dedicado a revisar abordagens e conteúdos sobre o ensino da geografia, levando em conta os desenvolvimentos recentes no campo, as transformações da sociedade contemporânea e as novas diretrizes curriculares para a Escola Secundária na Argentina. Analisamos também as seqüências didáticas, considerando o papel dos conceitos e explicações da ordem social nos conteúdos relacionados a problemas ambientais.

En investigaciones anteriores desarrolladas entre 2006 y 2010, detectamos distintos problemas en relación con la enseñanza de la geografía desde los enfoques actualizados propios de las ciencias sociales: abordajes disciplinares y didácticos que recuperan categorías de análisis y perspectivas metodológicas acordes con los principios que dan cuenta de la complejidad contemporánea, los conflictos y tensiones inherentes a la vida social, la multiplicidad de actores sociales y políticos implicados, la historicidad de los procesos socioterritoriales, entre otros.

De esos diagnósticos surge la inquietud por proponer nuevas puertas de indagación de las prácticas escolares, contribuyendo así a la transformación de los enfoques naturalizantes, acríticos o meramente descriptivos.

Esta idea fuerza constituye el propósito central que se enmarca en un momento histórico del desarrollo del nivel de enseñanza secundaria en Argentina, pues cobran plena centralidad los lineamientos político-institucionales, los pedagógico-didácticos y los referidos a las trayectorias escolares de los estudiantes en condiciones de igualdad y participación sancionados en la Ley Nacional de Educación 26206 (del año 2006).

En el proyecto de investigación que aquí comentamos, ofrecimos a un grupo de docentes de geografía de enseñanza secundaria, participar de una experiencia formativa, de intercambio y reflexión acerca de la elaboración de secuencias didácticas referidas a problemas ambientales.

El taller con los docentes tuvo entre sus objetivos revisar enfoques y contenidos acerca de la enseñanza de la geografía, teniendo en cuenta los desarrollos recientes del campo, las transformaciones de la sociedad contemporánea y los nuevos lineamientos curriculares para la escuela secundaria. También, analizar los contenidos y las estrategias didácticas desarrolladas en las planificaciones de aula, a fin de determinar qué papel ocupan los conceptos y explicaciones de orden social en los contenidos y problemas propuestos para la enseñanza; $y$, finalmente, discutir y reelaborar criterios de selección y organización de conteni- dos y de recursos pedagógicos para una enseñanza de la geografía que contemple los propósitos formativos más amplios prescriptos para el nivel secundario.

A partir del diálogo fructífero que se generó entre los participantes, y también de las producciones que se fueron elaborando, . OK abordamos distintos interrogantes que, si bien operaron como punto de partida en el trabajo con los docentes, en el desarrollo de la experiencia. OK develaron como preguntas genuinamente compartidas, que atraviesan distintos problemas de la enseñanza, en particular los referidos a la planificación.

\section{El trabajo en taller: productos y potencialidades}

Diversas razones justifican la metodología de taller, elegida para llevar a cabo esta propuesta de intervención académica e investigativa. Se trata de una dinámica de trabajo basada en las permanentes y recíprocas interacciones entre los docentes participantes y los docentes-investigadores y entre los mismos docentes entre sí. Esta modalidad de trabajo se constituye en un espacio privilegiado para experimentar otros modos de concebir la construcción del conocimiento, donde los participantes ponen en escena sus propios saberes, opiniones y creencias, que provienen tanto de sus experiencias profesionales y de vida como de las experiencias de pensamiento y modos de analizar la realidad que se configuran en el propio taller.

En esta interacción, quienes conducimos la experiencia estimulamos el diálogo; solicitamos la fundamentación de las opiniones o juicios que se enuncian en las charlas y debates; brindamos las herramientas necesarias y el acompañamiento para que pongan en práctica las producciones que previamente se elaboraron, ofreciendo orientaciones y sugerencias disciplinares y pedagógicas.

En el taller comenzamos por poner en discusión los abordajes tradicionales en geografía, en los que la selección de contenidos atiende a criterios propios de las perspectivas sistemáticas o regionalistas, que estudian los territorios como geografías naturales y no como espacios socialmente construidos en sus aspectos materiales y simbólicos. Esta decisión surge de los resultados de nuestras propias investigaciones, en las que se pudo constatar que los docentes no encuentran inconvenientes en enseñar una parte de los contenidos requeridos para el tratamiento de las problemáticas ambientales: aquellos que se vinculan con los contenidos de la geografía física (por ejemplo: hidrología, condiciones climáticas, tipos de relieve, biomas). Pero sucede que estos contenidos en general son enseñados en forma de listados poco conexos de nombres, datos y características. Por su parte, resulta limitada la incorporación de nuevos enfoques provenientes de ciencias naturales y físicas que abordan las 
cuestiones ambientales. Nos referimos, por ejemplo, a enfoques ecosistémicos, a la ecología regional y del paisaje, a las diversas visiones acerca de la conservación, a los servicios y funciones ambientales, etc.

Nuestro planteamiento acerca de la selección de contenidos para el abordaje de problemas ambientales procuró, desde una perspectiva socio-crítica de la geografía, articular contenidos físico-naturales con contenidos sociales, presentar en forma problemática un conjunto de contenidos que aparecían desconectados en el temario clásico y articular dinámicamente distintas escalas de análisis

Desde el punto de vista didáctico, definimos a las secuencias de enseñanza como trayectos de desarrollo de un contenido o tema-problema, compuesto por diferentes actividades en las que, de manera gradualmente ordenada, se despliegan los aspectos o dimensiones del objeto de estudio que se consideran más significativas. A través de las actividades que conforman la secuencia se abordan y se vinculan los contenidos seleccionados, sus conceptos y procedimientos de tal forma que la complejidad de los mismos se aborde en forma creciente.

Convinimos con los docentes en estructurar las secuencias referidas a problemas socialmente relevantes que involucraran cuestiones relativas a la dinámica natural, en torno a líneas temáticas que resulten orientadoras en la selección de contenidos, a saber:

- Gestión del riesgo, vulnerabilidad y desastres.

- Manejo de recursos naturales.

- Impactos negativos de las actividades productivas.

Para ello, organizamos cuatro grupos de trabajo, coordinados por las investigadoras del proyecto, que comenzaron el diseño y planificación de propuestas de enseñanza. Sobre la base de las coordenadas disciplinares y pedagógicas ya señaladas, los temas seleccionados por los docentes para estructurar las secuencias didácticas fueron:

- La problemática del acceso al agua potable en Argentina y el mundo.

- El avance de la frontera agropecuaria en la Argentina.

- La problemática ambiental en la cuenca Matanza-Riachuelo.

- Condiciones socio-ambientales y riesgo sanitario en países periféricos.

En términos generales, la selección de las problemáticas, contenidos, actividades y las fuentes escogidas resultaron pertinentes y adecuadas, y el trabajo de acompañamiento en el taller consistió en una lectura crítica y compartida orientada a enriquecer los respectivos productos.

A modo de ejemplo, podemos comentar que la presentación a los alumnos de la escuela secundaria, de la primera secuencia referida al tema del agua potable, se realizó a través de tres fotos convocantes, elocuentes, que evocan escenas de la vida cotidiana en tres contextos diferentes:
Burkina Faso, Indonesia e India. Luego se desarrolla una serie de actividades estratégicamente diseñadas para resolver las preguntas acerca de la renovabilidad del agua potable y del acceso desigual a este recurso. Las actividades fueron muy variadas en cuanto al tipo de consignas, de habilidades y el tipo de fuentes utilizadas: breves testimonios, gráficos y datos estadísticos, artículos periodísticos y textos bibliográficos. Así, los alumnos tuvieron oportunidad de pensar las preguntas a través de un repertorio amplio de información cualitativa y cuantitativa, dando lugar a reflexiones y debates, $y$, al mismo tiempo, a desarrollar aproximaciones conceptuales al problema de la sustentabilidad del recurso agua. Para dar una idea del trabajo pedagógico realizado con los contenidos, podemos señalar que algunas de las discusiones giraron en torno a la comparación entre las normas internacionales de calidad de agua en distintos países y los usos del agua; el análisis de situaciones referidas al problema de la falta de cloacas en el Gran Buenos Aires y los niveles de contaminación, y debates acerca del tema del libre acceso al agua potable en la provincia de Tucumán.

En cuanto a la evaluación de los resultados, según los propios profesores, la aplicación de la secuencia permitió a los alumnos desplegar variedad de opiniones e interpretaciones fundamentadas, así como reconocer distintos grados de avance en la comprensión del tema. Además, destacaron la buena receptividad por parte de los estudiantes, de la problemática, las actividades y las fuentes seleccionadas. Señalaron también que la propuesta abrió un espacio interesante para establecer conexiones con contenidos de otras asignaturas, especialmente los de Educación Cívica, en relación con el papel del Estado y las políticas públicas. Por último, rescataron el trabajo con diferentes escalas geográficas de análisis (mundial, nacional y local), estrategia que permitió ampliar la visión de ciertos procesos vistos.

En el caso de la secuencia referida a la expansión de la frontera agropecuaria en Argentina, se destaca la variedad de fuentes de información utilizadas (cartografía, imágenes satelitales, estadísticas, artículos periodísticos, textos académicos, material audiovisual, documentos normativos, leyes) y las diferentes propuestas de trabajo didáctico para abordar la información con cada una de estas fuentes. Toda la secuencia se diseñó apuntando a la problematización de los contenidos, sin desatender la enseñanza de herramientas instrumentales de análisis y la información básica necesaria e indispensable para pensar la problemática ambiental en su complejidad. Respecto del uso de recursos, cabe señalar que, como actividad de inicio, se presentaron imágenes satelitales del área de las Yungas del NOA (noroeste argentino) en diferentes momentos históri$\cos$ (1989 y 2000) a fin de comparar y visualizar las diferencias en el uso del suelo a lo largo del tiempo. Se propuso interpretar las cartas satelitales y elaborar hipótesis sobre las posibles causas de las diferencias observadas en las imágenes. A esto se sumó material audiovisual muy elocuente e impactante relacionado con la deforestación y el accionar de las máquinas en terreno. 
En la secuencia vinculada con la problemática ambiental en la cuenca Matanza-Riachuelo, como producto de las dificultades de la gestión ambiental, en particular en lo referente a la actividad industrial, la problemática seleccionada resulta muy significativa desde el punto de vista socio-ambiental, no solo por la gran cantidad de población local afectada, sino por la ampliación del problema y sus efectos a escalas geográficas más amplias. Ello obedece a que se trata de un caso paradigmático dentro de las problemáticas ambientales por su intensidad, la antigüedad de su origen, su persistencia a lo largo del tiempo, y por tratarse de una temática de gran controversia a nivel político y social, que implicó la generación de grandes movilizaciones sociales y una particular participación de organizaciones de la sociedad civil. Además, el caso de la contaminación en esta cuenca llegó a instancias judiciales. Por último, todas estas cuestiones fueron ampliamente difundidas en los medios de comunicación, por lo cual se trata de un tema conocido, en mayor o menor medida, por los alumnos.

Frente a una temática tan amplia y compleja, el acompañamiento en el taller se orientó especialmente hacia el ajuste en la selección de un eje temático que permitiera acotarla y resultara propicia para el trabajo en la cantidad de clases prevista, y que al mismo tiempo permitiera a los alumnos articular e hilvanar los principales aspectos del problema. De esta forma, se avanzó progresivamente en la elaboración de un "recorte" temático que constituyera un contenido pedagógico adecuado a los alumnos, a la disciplina y al tiempo escolar disponible para ser desarrollado. Se resaltó la importancia del marco histórico para la comprensión de la problemática, y se discutió acerca de la forma de vincular dicho marco con el problema, de modo tal que el sentido de "lo histórico" no se percibiera solo como una cuestión cronológica, sino como una cuestión intrínseca a la construcción del espacio que conforma la cuenca, y por lo tanto vinculada a las causas del problema. La actividad final resultó interesante en relación a la visualización de los aprendizajes logrados, ya que se proponía a los alumnos revisar las ideas previas planteadas en la primera clase.

En el caso de la propuesta vinculada con las condiciones socio-ambientales y riesgo sanitario en países periféricos, la selección del contenido ocupó un lugar destacado en la reflexión entre los docentes del taller. Se decidió trabajar sobre el eje de vulnerabilidad y sociedades en riesgo para abordar las problemáticas ambientales y el tema elegido para enfatizar la dimensión social de las problemáticas ambientales fue "las transformaciones ambientales y la sociedad en riesgo: la esquistosomiasis, una enfermedad hídrica".

Los componentes sociales fueron trabajados a lo largo de toda la secuencia, desde la modificación antrópica de las condiciones naturales del área en estudio, hasta los intereses y valores de los actores sociales involucrados, las cuestiones de salud y su relación con los procesos de desarrollo. La complejidad del problema abarcó la dimensión natural, tratada en los temas del ambiente del Nilo, sus características climáticas y edafológicas, a través del uso de material cartográfico y documental. También se relacionaron los contenidos físicos con cuestiones sociales, por ejemplo, al plantear las interrelaciones entre los usos de la cuenca, el aprovechamiento de las inundaciones y la configuración de una zona de riesgo de la enfermedad. En cuanto a la dimensión social, se hizo hincapié en las necesidades de abastecimiento energético para las zonas urbanas en detrimento de la calidad de vida de las zonas rurales. En relación con esto, se mostró la lógica que reside detrás de las decisiones políticas sobre el manejo del ambiente cuando se presentan proyectos de construcción de represas. Otro aspecto que se evidenció fue el impacto de la investigación sobre la esquistosomiasis, a partir de intereses de los países desarrollados de curar ciertas enfermedades, como alergias, más que de realizar acciones de prevención y tratamiento de enfermedades propiamente africanas.

\section{Reflexiones a partir de la investigación-acción}

Una primera conclusión obtenida a partir de la indagación realizada con docentes en ejercicio es la constatación de una fuerte y recurrente identificación de las cuestiones ambientales con el temario propio de la asignatura. La imagen pública de la geografía, las demandas sociales y culturales que a ella remiten, expresadas a través de los intereses de los alumnos y de las representaciones de la temática que manifiestan los estudiantes, docentes y padres, también justifican detenerse en el análisis de qué es lo que se enseña en materia ambiental, por qué presenta tanta aceptación, y cómo se desarrolla efectivamente esta práctica de enseñanza en las aulas. En virtud de los resultados obtenidos, consideramos que esta inclinación de los docentes de geografía al abordaje de temas ambientales podría encontrar explicación en dos cuestiones básicas: por un lado, la inclusión de contenidos vinculados con la geografía física, con la consecuente identificación de lo ambiental con aquellos contenidos que fueron la base de su formación inicial; y, por otro, la fuerte presencia de los temas ambientales en la agenda pública y en los medios de comunicación, como contexto propicio aprovechado por los docentes para generar interés en los alumnos.

La degradación de los recursos naturales, la pérdida de biodiversidad, la disminución de la productividad agrícola, los problemas de acceso al agua potable o la aparición de enfermedades infecciosas y parasitarias, son problemas cuyo análisis e interpretación requiere de un trabajo pedagógico que ponga en foco distintas instancias de ejercicio democrático: cuestionar argumentos, evaluar opciones, construir consensos, tramitar productivamente los disensos, imaginar y ponderar escenarios alternativos. Porque promover aprendizajes plurales y amplios en torno a estos problemas, colabora con el desarrollo de la palabra propia y brinda la oportunidad de elegir y aprender a hacerse responsable de las 
decisiones tomadas. Junto con sus pares y con la ayuda de los docentes, los alumnos ejercitan su capacidad de proponer, evaluar, sostener ideas y acciones.

En suma, como resultado de la experiencia relatada en estas páginas, sostenemos que un trabajo escolar que ponga en foco los dilemas éticos y políticos implicados en la agenda socioambiental contemporánea es una oportunidad inestimable para acercar a los jóvenes perspectivas que no asignen rasgos de inmutabilidad a los problemas socio-ambientales ni visiones que proyecten destinos inexorables; por el contrario, se trata de abrir un horizonte de comprensión y de acción para imaginar otros caminos, otros escenarios y prepararlos para ensayar, de manera informada y responsable, nuevas formas de construcción de ciudadanía.

\section{Referencias}

Audigier, F. (2002). Un estudio sobre la enseñanza de la historia, la geografía y la educación cívica en la escuela elemental de Francia: temas, métodos y preguntas. Enseñanza de las Ciencias Sociales. Revista de Investigación, 1, 3-16.

Bachmann, L. (2008). La educación ambiental en Argentina, hoy. Documento marco sobre Educación Ambiental, Dirección Nacional de Gestión Curricular y Formación Docente, Áreas Curriculares, Ministerio de Educación de la Nación. Buenos Aires.

Bocero, S., y Natenzon, C. (2007). La dimensión ambiental del territorio en América latina: aportes para su discusión. En M. Fernández y R. Gurevich (coord.), Geografía. Nuevos temas, nuevas preguntas. Un temario para su enseñanza. Buenos Aires: Biblos.

Carr, W. (1996). Una teoría para la educación. Hacia una investigación educativa crítica. Madrid: Morata.

Carr, W., y Kemmis, S. (1988). Teoría crítica de la enseñanza. La investigación acción en la formación del profesorado. Barcelona: Martínez Roca.

Elliot, J. (1994). La investigación acción en educación. Madrid: Morata

Elliot, J. (1997). El cambio educativo desde la investigación-acción. Madrid: Morata.

Fernández, M. (2011). Imaginarios culturales, valoración social y selección de contenidos en Geografía. En L. de Souza (org), Produção do conhecimento e pesquisa no ensino da geografia. Goiania: Ed Da PUC Goias.

Fernández, M. y Gurevich, R. (Febrero 15, 2010). La imagen pública de la geografía. Una indagación desde las visiones de profesores y padres de alumnos secundarios. Biblio 3W. Revista Bibliográfica de Geografía y Ciencias Sociales, 25(859). Recuperado de http://www.ub.es/geocrit/bw-ig.htm

Gurevich, R., Souto, P., y Ajón, A. (2010). Lo mismo, pero diferente. Contenidos y abordajes en Geografía frente a situaciones de desigualdad educativa. Plures Humanidades, 13, 12-32.

Gurevich, R., y Ajón, A. (año). Diálogos entre geografía y pedagogía. Espacios de Crítica y Producción, 46, 12-21.

Kemmis, S., y McTaggart, R. (1988). Cómo planificar la investigación-acción. Barcelona: Laertes.

Leff, E. (1999). Sociología y ambiente: formación socioeconómica, racionalidad ambiental y transformaciones del conocimiento. En E. Leff (comp.), Ciencias sociales y formación ambiental. Barcelona: Gedisa. 
Pérez Gómez, A. (2007). Aprender a enseñar. La construcción del conocimiento en la formación del profesorado. En Profesorado y otros profesionales de la educación. Madrid: MEC/Octaedro.

Schön, D. (1983). The Reflexive Practitioner. Nueva York: Basic Book

Schön, D. (1992). La formación de profesionales reflexivos. Hacia un nuevo diseño de la enseñanza y el aprendizaje en las profesiones. Barcelona: Paidós-MEC.

Senhouse, L. (1987). La investigación como base de la enseñanza. Madrid: Morata.

Souza de, L. (2011a). A formação acadêmica do professor de geografia: dimensões teóricas. Em C. H. Callai (org.), Educação geográfica. Reflexão e Prática (pp. 121-142) [Coleção de Ciências Sociais, 2]. ljuí: Editora Unijuí.

Souza de, L. (2011b). Ensinar geografia para a autonomia do pensamento: o desafio de superar dualismos pelo pensamento teórico crítico. Revista de ANPEGE, 7(1), 193-203.

Stenhouse, L. (1984). Investigación y desarrollo del currículum. Madrid: Morata.

Van Lier, L. (2001). Investigación-acción. Textos, 27, 81-88. 